Acta Hispanica (2014) 19: 79-100

\title{
BODAS DE SANGRE DE FEDERICO GARCÍA LORCA EN LAS TABLAS HÚNGARAS. ALGUNAS REPRESENTACIONES MEMORABLES ENTRE 1957-2014
}

\author{
ESZTER KATONA
}

\author{
Universidad de Szeged
}

\begin{abstract}
Resumen: La primera obra teatral de Federico García Lorca puesta en escena por una compañía húngara fue La casa de Bernarda Alba en 1955. La atención de los directores húngaros siguió con atención los dramas del artista andaluz, así, dos años más tarde, en 1957 el Teatro Nacional Húngaro puso en su programación otra obra, Bodas de sangre, escrita por el granadino en 1933. Desde entonces, la popularidad de esta pieza no ha disminuido nada en las escenas húngaras, incluso inspiró adaptaciones al baile y al teatro de ópera. Últimamente, en la temporada 2013-2014, el teatro Magyar Színház ha puesto en escena esta pieza y este estreno inspiró el presente ensayo cuyo objetivo es hacer un repaso sobre la recepción húngara de Bodas de sangre, destacando algunas representaciones importantes de las seis décadas pasadas.
\end{abstract}

Palabras clave: Federico García Lorca, Bodas de sangre, recepción húngara entre 1957-2014.

\begin{abstract}
The House of Bernarda Alba was the first play of Federico Garcia Lorca that was staged by a Hungarian company in 1955. Hungarian directors followed with close attention the dramas of the Andalusian playwright and two years later, in 1957, the Hungarian National Theater included on its program another play of Lorca, Blood Wedding, written in 1933. Since then, the popularity of this drama on Hungarian stages has not diminished at all, it also inspired dance and opera adaptations. Recently, in the 2013-2014 season, Magyar Szinbar theater has also staged this play. The aim of this paper, which has been inspired by the aforementioned premiere, is to offer an overview of the Hungarian reception of Blood Wedding, highlighting some important productions of the past six decades.
\end{abstract}

Key words: Federico García Lorca, Blood Wedding, hungarian reception between 19572014.

\section{Introducción}

Federico García Lorca se inspiró para escribir su obra Bodas de sangre en una noticia periodística de 1928 que relataba un misterioso asesinato en vísperas de una boda cerca del pueblo de Níar. El hombre muerto era el antiguo amante de la novia, que raptó a la chica por la noche antes de la boda, pero que recibió su castigo mortal a manos del 
Bodas de sangre de Federico García Lorca en las tablas húngaras.

Algunas representaciones memorables entre 1957-2014

hermano del novio. Es seguro que el artista granadino conoció esta historia de celos y venganza familiar a través de la prensa madrileña ${ }^{1} \mathrm{y}$, aunque cambió las relaciones familiares entre los personajes de la historia, conservó algunos detalles de la fuente real. ${ }^{2}$ En la versión de Lorca el asesinato será doble, ya que los rivales, el Novio y Leonardo se matan el uno al otro, mientras que la Novia, estigmada por su comportamiento que está contra la moral social, vuelve arrepentida al pueblo. Su apasionado monólogo explica a la Madre doliente la diferencia entre los dos hombres, caracterizando con claridad a los caracteres opuestos del Novio y Leonardo:

"Novia: ¡Porque yo me fui con el otro, me fui! (Con angustia) Tú también te hubieras ido. Yo era una mujer quemada, llena de llagas por dentro y por fuera, y tu hijo era un poquito de agua de la que yo esperaba hijos, tierra, salud; pero el otro era un río oscuro, lleno de ramas, que acercaba a mí el rumor de sus juncos y su cantar entre dientes. Y yo corría con tu hijo que era como un niñito de agua, frío, y el otro me mandaba cientos de pájaros que me impedían el andar y que dejaban escarcha sobre mis heridas de pobre mujer marchita, de muchacha acariciada por el fuego. Yo no quería, ¡Óyelo bien!; yo no quería, jóyelo bien!. Yo no quería. ¡Tu hijo era mi fin y yo no lo he engañado, pero el brazo del otro me arrastró como un golpe de mar, como la cabezada de un mulo, y me hubiera arrastrado siempre, siempre, siempre, siempre, aunque hubiera sido vieja y todos los hijos de tu hijo me hubiesen agarrado de los cabellos!" 3

El tema del amor perdido y no cumplido u obstaculizado por motivos sociales y/o materiales es fundamental en toda la obra dramática del granadino desde El maleficio de la mariposa (1920) hasta La casa de Bernarda Alba (1936). El destino trágico es inevitable también en el caso de los dos jóvenes de Bodas de sangre ya que no hay otra solución "que

${ }^{1}$ La noticia se publicó en $A B C$, el 25 de julio de 1928, cuyo texto reproduce Gibson. (Ian GIBSON, Federico García Lorca. I. De Fuente Vaqueros a Nueva York (1898-1929), Barcelona, Ed. Grijalbo, 1985. 554). Los reportajes y la investigación se publicaron en seis números del Heraldo de Madrid, 24-28 y 30 de julio de 1928.

${ }^{2}$ Por ejemplo, la Novia del drama vive con su padre porque su madre murió hace años, igualmente que Francisca Cañadas Morales, la novia verdadera de la historia criminal perdió a su madre. Además, según las crónicas, el antiguo amante de Francisca, Curro Montes Cañadas, que era además su primo, llegó primero a la boda. Al escuchar en secreto la disputa entre Francisca y su esposo futuro decide raptar a la joven en su caballo. Curro era un jinete experto como también la relación de Leonardo y su caballo es especial y será un elemento importante dentro del drama lorquiano. En la caracterización del Novio también tomó García Lorca los rasgos del novio verdadero, Casimiro Pérez Pino, un tipo tímido y obediente a las órdenes de su propia madre dominante. Gibson opina que en la figura de la Madre, García Lorca refleja, tal vez inconscientemente, a su propia madre, Vicenta Lorca. El instrumento asesino en la historia de Nijar fue una pistola convertida en una navaja, mucho más dramática y con una simbología densa también en la obra anterior -basta pensar en los poemas de los tomos Cante jondo y El romancero gitano - de García Lorca.

3 Federico GARCÍA LORCA, Bodas de sangre, asequible en: http://usuaris.tinet.cat/picl/libros /glorca/gl003900.htm, fecha de consulta: 2 de junio de 2014. Todas las citas posteriores de este drama tienen esta fuente.

80 |Acta Hispanica 19: 79-100, 2014, ISSN: 1416-7263 
seguir el camino de la sangre", las pasiones y la inclinación sin limitaciones incluso cuando eso les conduce inevitablemente al fracaso. La pasión mutua de Leonardo y la Novia no muere durante los años pasados separados, solo queda reprimida orgullosamente por las mencionadas expectativas familiares y sociales (orgullo de casta, matrimonio por interés). La justicia de la sociedad cuyo orden ha sido violado por la rebelión de los dos jóvenes desemboca en la tragedia: el resultado será la muerte violenta del Novio y Leonardo y la soledad de las tres mujeres, la Madre, la Novia y la mujer de Leonardo.

García Lorca, como hemos visto, extrae material de la vida real para escribir un drama rural, género muy cultivado también por otros dramaturgos de éxito. A diferencia de éstos, ${ }^{4}$ el dramaturgo de Fuente Vaqueros no se queda en la superficie de un puro costumbrismo, sino que logra crear una obra maestra con verdaderas pasiones humanas y con un lenguaje densamente metafórico. A partir de la fuga de los dos jóvenes, con la que finaliza el segundo acto, se quiebra y desaparece el realismo de la acción para dar paso a la fantasía poética. En el escenario del tercer acto ya aparecen personajes alegóricos, como la Luna y la Muerte, y pasajes de mucho lirismo, como la hermosa e insinuante canción de cuna (aún en el cuadro segundo del acto primero) o el coro de los Leñadores (en el cuadro primero del tercer acto).

Para todos los directores que quieren poner en escena esta tragedia -tal vez la pieza teatral más compleja de la obra dramatúrgica lorquiana- es una cuestión clave encontrar el equilibrio adecuado entre las situaciones reales y los elementos simbólicos y/o surrealistas. Encontrar este equilibrio no es fácil porque las figuras y los elementos míticos aunque están presentes ya desde el comienzo, sin embargo entran en la historia (y en el texto también) solamente en las últimas escenas, elevando la tragedia al nivel de la trascendencia poética. Si la aparición de estas figuras es inesperada, su efecto puede romper todo el espectáculo. Al contrario, si está preparada con cuidado, puede ocurrir que su presencia no cause el resultado deseado. Justamente por este motivo la dirección de Bodas de sangre es un gran desafío para todos los artistas, tanto directores, como actores.

En los años 50-60 la interpretación húngara de los dramas lorquianos era más realista de lo deseado. 5 La mayoría de los literatos y dramaturgos teatrales de aquel entonces consideraba también Bodas de sangre como una obra trágica de contexto campesino y pensaba que la estilización lírica y el toque surrealista de algunas escenas eran unos "accesorios" exteriores pero, sin duda alguna, muy interesantes. Solo pocos entendían que la sangre -que ya aparece en el título- no tenía un valor simplemente simbólico o algo que sugería el desenlace siniestro del drama, sino que era la clave de toda la obra. La sangre es la fuerza motriz y la protagonista de toda la acción. La huida

\footnotetext{
${ }^{4}$ Por ejemplo, el teatro costumbrista de los hermanos Álvarez Quintero, Serafín (1871-1938) y Joaquín (1873-1944), el teatro poético de Eduardo Marquina (1879-1946), o los dramas rurales de Jacinto Benavente (1866-1954).

${ }^{5}$ Géza FODOR, "Látomás és indulat az operában Szokolay Sándor: Vérnász - Magyar Állami Operaház”, in: Muðsika, noviembre de 2003, 28.
} 
Bodas de sangre de Federico García Lorca en las tablas húngaras.

Algunas representaciones memorables entre 1957-2014

de Leonardo y la Novia no es simplemente la culminación de una acción psicológica sino que es la manifestación de la fuerza de la sangre. La enunciación fatal de la Madre - "Ha llegado otra vez la hora de la sangre."- eleva la vendetta determinada por las leyes sociales al nivel ancestral de las fuerzas naturales. "La sangre" del título y "la oscura raíz del grito" de la última frase de la obra antes de caerse el telón, determinan todo el ambiente escénico que está mucho más allá del realismo decimonónico ${ }^{6}$ de las obras rurales de los dramaturgos españoles mencionados.

Hay que ver, pues, que la dramaturgia lorquiana no es realista a secas, porque García Lorca debajo de la superficie realista en todos los momentos hace un ingenioso juego dramático tanto con las partes líricas como con el simbolismo cromático, acústico y espacial. Observando tal característica, un dramaturgo de hoy ya no puede considerar el repentino cambio de la prosa en poesía como un simple cuadro de género folclórico por ejemplo, la nana del segundo acto- sino como un importante cambio de dimensión.

Generalmente, las primeras puestas en escena captaron el surrealismo de la obra solamente en el primer cuadro del último acto (la escena del bosque con los Leñadores) y no prestaron mucha atención, por ejemplo, a la escena de las tres muchachas que están devanando una madeja roja, alusión evidente a las Parcas mitológicas, símbolos del fatum. Por consecuencia, el drama rural realista de la primera lectura superficial, Bodas de sangre, se convierte en una pieza teatral con denso valor lírico, simbólico y mitológico. Así, para lograr una adecuada interpretación, el director tiene que encontrar el equilibrio, muy frágil, entre lo elevado y lo cotidiano, entre la estilización y el realismo. ${ }^{7} \mathrm{Y}$ eso es lo que evidentemente dificulta la puesta en escena de esta obra maestra.

Por supuesto, para un espectáculo húngaro, el director necesita una traducción de la obra. Las primeras puestas en escena utilizan la traducción magistral ${ }^{8}$ de Gyula Illyés. ${ }^{9}$ Desde la dirección de Eszter Novák podemos ver un cambio respecto al texto utilizado ya que después de 1996 los directores prefieren la nueva traducción de Zsuzsanna Gajdos y Miklós Veress, y ya solo pocos vuelven a la primera versión húngara.

\footnotetext{
${ }^{6}$ Aquí pienso es necesario hacer la distinción entre el realismo como categoría estética y el realismo como corriente literaria de la segunda mitad del siglo XIX.

7 Tamás KOLTAI, "Benne vannak a korban", in: Élet és Irodalom, 14 de noviembre de 2008.

${ }^{8}$ Gábor GODA, “A vérnász kése”, in: Élet és Irodalom, 10 de mayo de 1957.

${ }^{9}$ La primera traducción del drama apareció justamente en 1957, en el libro Toreádorsirató. Válogatott költemények és színminvek [Poesía y teatro selecto de Federico García Lorca], Budapest, Európa, 1957. Aquel tomo contenía aún la traducción de László András - que dio el título Vérmennyegző- y solamente en la siguiente publicación, del mismo año, llegó al público el drama en la interpretación húngara de Gyula Illyés (Federico GARCÍA LORCA, Vérnász, Budapes, Európa, 1957). La traducción del título de la obra, en húngaro Vérnáš, parece una solución muy acertada. Sin embargo, hay que mencionar que eso no solamente elogia al traductor sino más bien a Mihály Vörösmarty ya que el poeta más importante del Romanticismo húngaro intituló así su tragedia de cinco actos en 1834, obra premiada por la Academia de Ciencias de Hungría.
} 


\section{El primer estreno de Bodas de sangre en Hungría (1957)}

El primer director húngaro que puso en escena una obra teatral de Federico García Lorca fue Endre Marton, director de La casa de Bernarda Alba en el Teatro Katona József en 1955. Por el éxito de aquel estreno, dos años más tarde, el Teatro Nacional de Budapest puso en su cartel también el drama Bodas de sangre con el mismo director.

Los espectadores y los críticos de teatro de los años cincuenta, al ver La casa de Bernarda Alba aplaudieron sobre todo las aspiraciones realistas de García Lorca, categorizando al dramaturgo como un "escritor del pueblo" y eso armonizaba perfectamente con el realismo popular de la tendencia literaria húngara. ${ }^{10}$ En el caso de Bodas de sangre los artistas húngaros -tanto los directores, como los actores o los escenógrafos- se encontraron con una tarea muy diferente y mucho más difícil, ya que en esta obra el realismo está mezclado con un fuerte lirismo. ${ }^{11}$ Así, no es posible poner en escena esta obra como un puro drama rural, ya que sus personajes no son simples campesinos, sino que, ante todo, son hombres y mujeres de sentimientos humanos muy universales. Así, Lorca tampoco se sumerge en el provincialismo o en el dialectalismo: no es un sociólogo, sino un dramaturgo poético y, a la vez, un poeta dramático. ${ }^{12}$

La mayoría de las críticas sobre este estreno elogian el trabajo del director, destacando la dificultad que ofrece la tragedia misma por la mencionada combinación del realismo con lo fantástico ${ }^{13}$, lo surrealista ${ }^{14}$, lo estilizado ${ }^{15}$. El elemento poético del drama es lo que distingue esta obra de otros dramas rurales y, si el director se olvida de este factor, comete un grave error. Lo cometieron algunos de los directores extranjeros también -opina Tolnai- que guardaban solo la faceta realista de la obra, asegurando así la homogeneidad de los tres actos. Esta concepción, sin embargo, quita por completo lo poético, o, según algunos, "lo romancesco", aludiendo abiertamente a la estrecha relación que une el ambiente de las piezas del Romancero gitano con el de Bodas de sangre. Afortunadamente -sigue Tolnai-, Endre Marton eligió otro método: él guardó fielmente lo estilizado del tercer acto e introdujo algunos elementos estilizados (por ejemplo, la pantomima de la Luna y la Mendiga/Muerte) ya en las dos primeras partes, garantizando de tal manera la unidad de los tres actos. ${ }^{16}$

${ }^{10}$ Entre los escritores de esta tendencia hay que destacar a Gyula Illyés -que, además, por esta afinidad será un excelente traductor de más dramas lorquianos- Zsigmond Móricz, László Németh, Áron Tamási.

11 Gábor TOLNAI, "Vérnász. García Lorca drámájának bemutatója a Nemzeti Színházban”, in: Népszabadság, 12 de mayo de 1957.

12 Gábor, GODA, op. cit.

${ }^{13}$ Imre DEMETER, “García Lorca: Vérnász. Bemutató a Nemzeti Színházban”, in: Esti Hírlap, 21 de abril de 1957.

${ }^{14}$ Jenő KATONA, "Vérnász”, in: Nagyvilág, 1957, 4, 619.

${ }^{15}$ Gábor TOLNAI, op. cit.

${ }^{16}$ Ibidem. 
Bodas de sangre de Federico García Lorca en las tablas húngaras.

Algunas representaciones memorables entre 1957-2014

La crítica de Jenô Katona ${ }^{17}$ destaca el profundo dramatismo y el realismo de los dos primeros actos, pero condena severamente el surrealismo del tercer acto. Los diálogos instintivos y muy acertados tanto respecto a la situación como al carácter de los personajes, en la última parte del drama se convierten de repente en unos recitados retóricos - según Katona. El periodista critica que el dramatismo se transforma en lirismo que, según su opinión, no es muy compatible con la tradición teatral. Yo, personalmente no comparto el juicio del autor, incluso podríamos preguntar por qué se excluirían el uno al otro. Es bien sabido que el mundo teatral de García Lorca está lleno de lirismo como también su lírica es densamente dramática, basta pensar en el dramatismo de los famosos poemas del emblemático y ya citado Romancero. En este punto es interesante contrastar la crítica mencionada con el análisis muy elogiador de Goda que ve la grandeza artística de García Lorca justamente en su capacidad de mezclar tan naturalmente lo estilizado con lo real cuyo efecto es impresionante - dice Goda. ${ }^{18}$ Aunque afirmo que Jenő Katona tiene también razón cuando habla sobre una equivocación del director: dar el papel de la Luna a un actor (Tamás Major) -en vez de una actriz- es una idea errada ${ }^{19}$, y su actuación será incluso ridícula cuando en su monólogo el astro de la noche habla sobre "los montes de mi pecho". Este inexplicable cambio de género confunde la simbología no solo lorquiana sino la universal también, ya que la luna es un principio femenino desde la antigüedad.

Todos los artículos que analizan la dirección de Marton elogian tanto el trabajo de las actrices (Erzsi Somogyi, Erzsi Máthé, Katalin Berek, Mária Sivó, Frida Gombaszögi), y los actores (Ferenc Kállai, Gyula Buss, Endre Szemethy) como la escenografía (Gyula Hincz) y el vestuario (Piroska Laczkovicz). La opinión de Goda es, tal vez, la más deslumbrada, llegando a la siguiente conclusión: "Si García Lorca pudiera ver su propia obra en el Teatro Nacional, estaría totalmente conforme con la dirección." 20

\section{Teatro Jókai de Békéscsaba, dirección de Béla Udvaros (1981)}

El director del estreno de marzo de 1981, Béla Udvaros, mencionó en una entrevista que la posibilidad de poner en escena Bodas de sangre era antiguo sueño suyo. Se encontró por primera vez con García Lorca en 1960 cuando dirigió La casa de Bernarda Alba en el Teatro Katona József de Kecskemét. Es decir, de manera similar a Endre Marton, el director del primer estreno húngaro de esta obra, Béla Udvaros tuvo también experiencia previa con un drama lorquiano. En la entrevista citada el director

\footnotetext{
17 Jenő KATONA, op. cit., 619-620.

18 Gábor GODA, op. cit.

${ }^{19}$ Lamentablemente muchos de los directores posteriores (Béla Udvaros, Eszter Novák,... etc.) han dado el papel de la Luna a un actor, aunque, con la retraducción de la obra la nueva versión húngara pudo evitar las referencias "al pecho" del astro luminoso y así eludir esta ambivalencia sexual.

${ }^{20}$ Gábor GODA, op. cit.
} 
expresa su profunda admiración por García Lorca y considera al dramaturgo granadino como un hombre de teatro ejemplar: "Cuando el teatro perdió cada vez más su lirismo, justamente en aquel momento llegó García Lorca y realizó la gran síntesis del drama y de la poesía." ${ }^{21}$ Udvaros en este aspecto encuentra la grandiosidad del artista español y por eso, como explica, sus obras teatrales pueden darnos una experiencia compleja, ya que la hermosura de la poesía intensifica el conflicto dramático.

A pesar de eso, podemos decir que el director no logra realizar esta fusión en las tablas del Teatro Jókai: subraya más bien el lado realista de la historia y queda en deuda con el lirismo. Aunque no elimine por completo del reparto los papeles de la Luna ${ }^{22}$ y de la Muerte, su función es muy desdibujada y pierden su fuerza dramática. ${ }^{23}$

El crítico del periódico Népszabadság también echa de menos el dramatismo de la obra, degradando la dirección de Udvaros a una fábula. Su severa opinión deja elogiar solamente la escenografía, único elemento del espectáculo fiel a la tragedia. Sin embargo, eso no pudo salvar la función - concluye secamente el periodista. ${ }^{24}$

Sin embargo, podemos encontrar en la prensa local una voz más positiva también sobre el espectáculo. Andódy destaca algunas soluciones buenas del director aunque, en la mayor parte de su recensión, elogia más bien la genialidad de García Lorca y no tanto la concreta puesta en escena. Es delator también que para el periodista la mayor impresión se la causara la traducción de Gyula Illyés que tenía "una claridad como un arroyo". ${ }^{25}$

\section{Bodas de sangre sin sangre: dirección de Eszter Novák (Új Színház, 1996)}

La primera curiosidad del estreno de Új Színház en 1996 fue que, por fin, una directora hizo la puesta en escena. En el caso de La casa de Bernarda Alba este elemento es muy importante ya que aquella obra es un verdadero drama de mujeres, protagonizado por caracteres femeninos muy fuertes. Así, pienso que la cuestión del género del director no puede ser indiferente en el caso de La casa..., visto que una mujer pude sentir desde dentro la situación de las mujeres frustradas. ${ }^{26}$ Aunque Bodas de sangre tiene un reparto mucho más equilibrado desde el punto de vista del sexo de los personajes, no podemos declarar entonces que fuera una obra tan evidentemente

${ }^{21}$ Ervin SASS, "Lorca: Líra és dráma nagy szintézise. Udvaros Béla a Vérnászróll, in: Békés Megyei Népújság, 15 de marzo de 1981.

22 Semejantemente a la dirección de Marton (Teatro Nacional, Budapes, 1957), también el director del estreno de Békéscsaba da el papel de la Luna a un actor (István Imre), una decisión no muy acertada.

${ }^{23}$ Erzsébet ÉZSIÁS, "Vérnász. Lorca-bemutató Békéscsabán", in: Új Tükeör, 26 de abril de 1981.

24 T. E., "Vérnász. García Lorca drámája a békéscsabai Jókai Színház előadásában”, in: Népszabadság, 3 de junio de 1981.

25 Tibor ANDÓDY, “Vérnász”, in: Békés Megyei Népújság, 4 de abril de 1981.

${ }^{26}$ Entre las directoras de La casa de Bernarda Alba destacaría a Judit Nyilassy (Miskolc, 1968), Kati Lázár (Kaposvár, 1985), Erzsébet Gaál (Szeged, 1996), Erika Szántó (Győr, 2000), Judit Galgóczy (Debrecen, 2005). 
Bodas de sangre de Federico García Lorca en las tablas húngaras.

Algunas representaciones memorables entre 1957-2014

"femenina", aunque podemos decir que los papeles de las mujeres dentro de este drama son mucho más fuertes que los de los hombres. ${ }^{27}$ Eszter Novák, la directora del espectáculo de 1996, sintió muy bien este rasgo y aún percibió perfectamente que entre las figuras femeninas había una jerarquía según su dolor y su resignación hacia su propio destino. Las actrices ${ }^{28}$ de su espectáculo actúan según este criterio. Por eso, uno de los críticos opina que se trata de un espectáculo femenino: la concepción dramatúrgica acentúa este carácter matriarcal de la sociedad retratada. ${ }^{29}$

Otra novedad de la dirección de Eszter Novák es que por primera vez la directora no utilizó la traducción de Illyés -elogiada por muchos- y tuvo el coraje de romper esta tradición, retraduciendo y adaptando al espectáculo el texto lorquiano. Zsuzsanna Gajdos tradujo las partes en prosa, mientras que Miklós Veress se encargó de los pasajes líricos. Los críticos destacan este cambio y aprecian el lenguaje conciso y muy rico en metáforas $^{30}$ utilizado por los dos traductores, aunque a veces lo juzgan demasiado elocuente. ${ }^{31}$ Según otros, el gran mérito de Gajdos y Veress es que -respecto a la primera versión de Illyés- los traductores nuevos hicieron una versión mucho más seca, aunque lírica, y libre del folclorismo exagerado. ${ }^{32}$ Sin embargo, en este espectáculo tampoco está ausente el folclor pero no aparece en el lenguaje sino que en la música y en el baile que mezclan elementos españoles, húngaros y gitanos. Tal vez Novák fuera motivada por la ópera de Szokolay y por la película musical de Carlos Saura protagonizada por Antonio Gades y Cristina de Hoyos

El primer encuentro de Eszter Novák y García Lorca fue en 1993, cuando la directora, recién diplomada, puso en la Escena Ódry, teatro de la Universidad de Artes Escénicas de Budapest, La tragicomedia de Don Cristóbal y Doña Rosita. Respecto a esa farsa, Bodas de sangre fue una obra verdaderamente difícil, pero la dramaturga logró solucionar bastante bien la tarea. Novák también logra combinar el realismo con la poesía y, de manera semejante al ejemplo de Marton (Teatro Nacional de Budapest, 1957) intenta introducir el mundo lírico y trascendental ya en los dos actos primeros.

27 García Lorca imaginó en este drama seis papeles femeninos (la Madre, la Novia, la Mujer de Leonardo, la Suegra, la Criada y la Vecina) y tres masculinos (Leonardo, el Novio y el padre de la Novia). Los personajes alegóricos (la Muerte y la Luna) están escritos básicamente para mujeres, aunque -como hemos visto- los directores pueden tener diferentes concepciones artísticas sobre esta cuestión, mientras que el coro de los leñadores (tres hombres) suele reforzar el lado masculino del reparto.

${ }_{28}$ Mari Csomós (la Madre), Ildikó Tóth (la Novia), Erika Marozsán (la mujer de Leonardo), Olga Koós (la Suegra), Kati Lázár (la Criada), Kati Berek (la Vecina).

${ }^{29}$ István SÁNDOR L., "Belső dráma. Federico García Lorca: Vérnász”, in: Színház, junio de 1996. 28-31.; Balázs LÉVAI, “Asszonyok Hispániából. Vérnász a Paulay Ede utcában”, in: Magyar Narancs, 4 de abril de 1996.

30 Tamás KOLTAI, "Demonstráli, ahogy tetszik", in: Élet és Irodalom, 12 de abril de 1996.

${ }^{31}$ GIG-LI, "Szaharin. A Vérnász az Új Színházban”, in: Demokrata, 1996. 27. 4 de julio de 1996. 57.

32 Judit Katalin MAGYAR, "Vérnász vér nélkül. Lorca-bemutató az Új Színházban", in: Népsqava, 30 de marzo de 1996. 


\section{Eszter Katona}

Así, las dos figuras alegóricas, la Muerte y la Luna son testigos presenciales de todas las escenas, con su actuación silenciosa sugieren in crescendo el aumento de la tensión y, desde este aspecto, algunas soluciones hermosas merecen un gran aplauso. Por ejemplo, resulta un gran momento lírico cuando la Luna (Virgil Horváth) viste a la Novia (Ildikó Tóth) en un vestido negro y luego se quedan abrazadas durante algunos minutos, mientras que en el fondo, a modo de fuerte contraste, están los alegres invitados de la boda. Más tarde, la Muerte, que en realidad es la pareja siniestra de la Luna, disemina semillas de trigo, símbolo de la fecundidad sobre los recién casados. ${ }^{33}$ Otra idea impresionante es que el Novio tiene que elegir a su Novia entre unas mujeres con velo. El joven elige y abraza a una de las muchas pero cuando el velo se cae y deja descubierta la cara de la mujer elegida, se ve que el Novio está abrazando a la Muerte y no a la Novia. Es una pena que justamente en el tercer acto, cuando, según Lorca, tendrían que asumir la iniciativa convirtiéndose en figuras principales, la fuerza de las dos palidezca marcadamente. Se pierde así la tensión y el espectáculo se agota y es por eso que algunos critican la duración de la obra. ${ }^{34}$

García Lorca no visualiza el duelo de los dos hombres, solamente a través de los diálogos llegamos a conocer el desenlace trágico. ${ }^{35}$ Así, siempre resulta curiosa la solución de las diferentes puestas en escena. Hay algunos directores que quieren aprovechar la visualización de la sangre visto que su efecto puede ser muy fuerte. ${ }^{36}$ Sin embargo, personalmente pienso que la maestría dramatúrgica de García Lorca reside entre muchas otras cosas, por supuesto- justamente en el hecho de que no nos muestra los hechos en su realidad fría, solo los insinúa. Como tampoco vemos a Pepe el Romano en su caballo, ni el ahorcamiento de Adela al final de La casa de Bernarda Alba, así tampoco asistimos a la muerte sangrienta del Novio y Leonardo. Eszter Novák, fiel a la concepción lorquiana, imagina una matanza sin sangre y pone el énfasis más bien en los antecedentes y en las consecuencias del encuentro mortal.

A pesar del aumento gradual de la tensión y de la fuerza de algunos grandes momentos del espectáculo, las pasiones no llegan a la explosión esperada. La tragedia se tranquiliza y se transforma en una balada, ${ }^{37}$ en unas bodas sin sangre, ${ }^{38}$ y no solamente por no hacer visible en las tablas el rojo humor vital. Como si la detonación se realizara

\footnotetext{
${ }^{33}$ Balázs LÉVAI, op. cit.

${ }^{34}$ Representaron la obra sin pausa. (MGP, “Szünet nélkül”, in: Népszabadság, 18 de narzo de 1996.)

35 El método será semejante en La casa de Bernarda Alba, en la que -según el texto lorquianotampoco vemos la escena del suicidio de Adela. Así, es una cuestión importante de una puesta en escena concreta cómo soluciona el director la interpretación de este acto violento.

36 Por ejemplo, Ádám Horgas, en su dirección de 2013 en el teatro Magyar Színház sí que utilizó la fuerza dramática de la sangre.

${ }^{37}$ Miklós GYÖRFFY, “Tragédia balladában elbeszélve. Lorca Vérnásza az Új Színházban”, in: Magyar Nemzet, 3 de abril de 1996.

${ }^{38}$ Judit Katalin MAGYAR, op. cit.
} 
Bodas de sangre de Federico García Lorca en las tablas húngaras.

Algunas representaciones memorables entre 1957-2014

debajo del agua, ${ }^{39}$ agitando un poco la superficie pero sin la purgación de la catarsis final. Es decir, justamente la fuerza dramática hace falta del espectáculo como si el conflicto se desarrollara no entre los personajes sino dentro de ellos. ${ }^{40}$

Junto con los defectos -o tal vez mejor hablar sobre imperfecciones- de la puesta en escena, la dirección recibió numerosos elogios y es digno de mención que dos actrices, Mari Csomós (la Madre) y Kati Lázár (la Vecina) recibieron los premios prestigiosos de los críticos en 1996. ${ }^{41} \mathrm{Y}$, aunque no se concede este premio a espectáculos enteros, uno de los críticos dijo lo siguiente: "Por el elevado nivel tanto de la dirección y la interpretación de los actores como de la escenografía y el vestuario yo daría el premio de "la mejor función" a «Bodas de Sangre». Lamentablemente el jurado del Premio de los Críticos aún no haya introducido esta categoría." 42

Podemos considerar igualmente elogiadora la opinión de Balázs Urbán ${ }^{43}$ cuando dice que todas las puestas en escena húngaras de Bodas de sangre quedan en deuda con la expresión del duende lorquiano, y solo la dirección de Eszter Novák pudo acercarse mejor a la atmósfera del universo de García Lorca.

\section{Versión gitana de la compañía Vareso Aver, dirección de Zoltán Lendvai (2000)}

Transponer la historia de García Lorca a un contexto gitano parece una concepción dramatúrgica evidente. La utilizó también Zoltán Lendvai en su dirección de 2000 realizada con la compañía Vareso Aver ${ }^{44}$ un grupo ocasional de actores gitanos y no gitanos, antecedente del futuro teatro Maladaype. ${ }^{45}$

La singularidad principal del estreno fue que la historia se emplazó no en un escenario artificial, sino que en un ambiente cotidiano, en el edificio del Parlamento Romaní, ${ }^{46}$ concretamente en sus espacios interiores, en la escalera y en el patio, de tal manera que el público estuviera siempre en movimiento siguiendo a los actores. También el vestuario se parecía a la ropa diaria de los actores. Con este método, en un primer momento los espectadores no podían diferenciar quiénes formaban parte del espectáculo y quiénes pertenecían al auditorio. Una solución aplaudible fue la

\footnotetext{
${ }^{39}$ GIG-LI, op. cit.

40 István SÁNDOR L., "Belső dráma...”, op. cit., 28.

${ }^{41}$ Sobre el premio véase la revista $S_{\text {zinház }}(1996$, número 10), asequible en: http:/ /www.szinhaz.net/ pdf/1996_10.pdf, fecha de consulta: 4 de junio de 2014, y merece la atención sobre todo la opinión de Katalin Budai y la de István Sándor L. (páginas 7 y 16).

${ }^{42}$ István SÁNDOR L., en: http://www.szinhaz.net/pdf/1996_10.pdf, 16, fecha de consulta: 4 de junio de 2014.

${ }^{43}$ Balázs URBÁN, "Már megint a duende", in: Criticai Lapok, 20 de diciembre de 2008.

${ }^{44}$ Una expresión en romaní, quiere decir algo diferente.

45 El teatro Maladaype (la palabra significa encuentros) fundado en 2001 por Zoltán Balázs, empezó su trabajo como teatro independiente.

${ }^{46}$ En la calle Nagymező de Budapest.
} 
incorporación del público, por ejemplo, a la escena de la boda -escenificado en el patio del edificio- para que se formara una muchedumbre tirando arroz a los recién casados.

En este espectáculo no hubo ninguna artificialidad escénica. No solamente el vestuario y el escenario eran reales, sino que también la fijación temporal del espectáculo era muy ingeniosa: durante las nupcias se puso el sol y así la escena de la fuga y la persecución ya se desarrolló al anochecer, entre la luz de las antorchas. Con esta inmersión del público, la última escena tuvo un efecto brutal: parecía como si los espectadores hubieran asistido realmente a un asesinato, contemplando la lucha de los dos hombres rivales desde el balcón del edificio. ${ }^{47}$

Aunque el espectáculo tuvo solamente dos estrenos, podemos considerarlo como una iniciativa singular ya que fue un espectáculo gitano (en lengua romaní, con actores y música gitanos) galardonado con el premio Civiseuropa (categoría dramática) concedido por el Foro Europeo. ${ }^{48}$

\section{Teatro Móricz Zsigmond, Nyíregyháza, dirección de Péter Forgács (2001)}

El reparto de la dirección de Forgács ya lleva algunas novedades y es un poco diferente del canon lorquiano. La Madre, por ejemplo, no es una mujer anciana amargada por el luto y la venganza, sino una mujer enérgica enviudada prematuramente. Tampoco el actor que interpreta al personaje de Leonardo es un macho radiante, más bien es un hombre ensimismado que se atormenta sin cesar. Es interesante la elección de Forgács también para el papel de la Novia ya que la actriz que interpreta este personaje, con su pelo rubio, parece una mujer escandinava y no una prometida de sangre mediterránea. Es extraña también la relación entre la Madre y su hijo, más sensual de lo normal, y cuando se besan en sus bocas podemos sentir con razón que su contacto corporal y emocional es mucho más fuerte que el vínculo entre el Novio y la Novia. ${ }^{49}$ Se percibe un erotismo incluso en la relación entre el Novio y la Criada y este motivo es también bastante ajeno de las relaciones interpersonales del reparto de García Lorca.

A pesar de estos cambios en la naturaleza de los personajes, el primer acto guarda básicamente el realismo de la historia. No así el segundo acto y la escena de la boda, que están llenos de soluciones sorprendentes y poco habituales aunque, en su conjunto, es un juego agradable y espiritoso. Forgács abre el espacio y crea un espectacular rito

\footnotetext{
47 "Cigányvérnász", in: http://szinhaz.hu/component/content/article/13-archivum/7049, fecha de consulta: 15 de junio de 2014.

48 "Európa díjas a cigány Vérnász", in: http://www.origo.hu/teve/20011107europa.html, fecha de consulta: 15 de junio de 2014.

${ }^{49}$ Es llamativo que también la dirección de Rusznyák (Teatro Honvéd, 2008) subraya esta estrecha relación corporal entre la madre y su hijo semejantemente a través de un beso en la boca entre el Novio y la Madre.
} 
Bodas de sangre de Federico García Lorca en las tablas húngaras.

Algunas representaciones memorables entre 1957-2014

multicultural con música viva, baile y diversión bulliciosa. La cara pintada de color oroamarillo de los personajes, su vestuario muy decorado y de color alegre evocan mucho más unas nupcias indias que una boda andaluza, aunque la coreografía mezcla elementos del folclor húngaro con los característicos movimientos de bailes indios y flamencos. La música, los efectos acústicos (chasquidos, pataleos, aplausos) y la coreografía se elevan al mismo rango del texto ritmando la acción, y la combinación de todo eso es verdaderamente estética y expresivo - opina Perényi. ${ }^{50}$

Varias veces he aludido a la problemática interpretación escénica del elevado lirismo del tercer acto de Bodas de sangre, que los directores muchas veces no pueden solucionar adecuadamente y, por eso, prefieren abreviar y transformar las partes poéticas de los Leñadores, la Luna y la Muerte. También la producción de Nyíregyháza fracasa totalmente en este punto. Después del realismo correcto del primer acto y la agitada visión sensual de la segunda parte, el tercer acto con su caos estilístico deja decepcionados a los espectadores. Ya que Forgács en las dos partes anteriores no prepara adecuadamente la aparición de los elementos surrealistas, la escena de los Leñadores, o mejor dicho, unos elfos ridículos, es incomprensible, como lo es también la escena de los niños jugando al marro. Es un error dramatizar - en vez de poetizar- la figura de la Luna, que en su abrigo de color plata recuerda más bien a un mago ucraniano de mal gusto - dice la crítica severa. ${ }^{51} \mathrm{Ni}$ la Luna ni la Muerte pueden elevarse a un nivel de poderío demoníaco ${ }^{52}$ y así el ambiente del tercer acto no llega a ser un mundo surrealista sino que queda en una visión caótica y desordenada sin concepción dramatúrgica. Es una pena que el ardiente misterio del amor no se transforme en el sangriento misterio de la muerte y que Forgács no encuentre el equilibrio entre los diferentes niveles, clave del éxito de todas las puestas en escena, al que ya he aludido en la introducción.

\section{El teatro Honvéd, dirección de Rusznyák Gábor (2008)}

El cartel del espectáculo del teatro Honvéd anuncia la obra como "duende en una parte", así no podemos evitar la consideración de este concepto tan lorquiano. Es un hecho que la clave de las interpretaciones de las obras de García Lorca es realmente la creación de una atmósfera peculiar que en todos los momentos lleva en sí la posibilidad de la tragedia y que es capaz de sugerir que el mundo representado funciona según unas leyes especiales. ${ }^{53}$ En este universo duendesco una lírica delicada se junta con una ardiente tensión dramática y la realidad se mezcla con el surrealismo de una manera muy natural. ¿Cómo realizó esta tarea este estreno?

\footnotetext{
${ }^{50}$ Balázs PERÉNYI, “Andalúz revü Indiából”, in: Szinház, 2002. 3. 9-10.

${ }^{51}$ Ibidem, 10.

52 Balázs URBÁN, “A forma ereje”, in: Ellenfény, 2002, 1, asequible en: http://www.ellenfeny.hu/ archivum/2002/1/a-forma-ereje, fecha de consulta: 16 de junio de 2014.

${ }^{53}$ Balázs URBÁN, "Már megint a duende”, op. cit.
} 


\section{Eszter Katona}

La concepción de Rusznyák no logra transmitir el mundo simbólico del drama formula en su crítica Urbán- sobre todo porque borra casi por completo el papel de la Muerte y la Luna. Aunque estas figuras aparecen en la escena, prácticamente no tienen ninguna importancia y es por eso que el nivel surrealista pierde su fuerza y el lado realista de la historia cobra dominancia. El secreto, la omisión y la tenebrosidad, es decir los componentes del famoso duende, son los que faltan del espectáculo. ${ }^{54}$

Sin embargo es interesante contrastar la opinión antes citada con la de Koltai ${ }^{55}$, que elogia el trabajo del director justamente desde el punto de vista de la fusión de la lírica estilizada con el drama realista. Es decir, según la opinión de Koltai -y pienso que es un gran elogio- Rusznyák solucionó el punto más problemático de Bodas de sangre de Federico García Lorca.

Leyendo las críticas de las revistas teatrales sobre este estreno es sorprendente que más de éstas busquen analogías shakesperianas. ${ }^{56}$ Kalapos $^{57}$ apostrofa la obra como una versión española de la historia de Romeo y Julieta, evidentemente por el rencor que guarda la familia del Novio por la de Félix, parientes de Leonardo. El mismo artículo alude también a otro paralelismo entre el coro de los leñadores y la función del sepulturero hamletiano. Urbán hace también una alusión a la obra shakespeariana cuando opina que la Madre del Novio (o más bien la interpretación de la actriz) no llega a la altura de una heroína dramática de García Lorca, sino que queda más bien una pálida señora de Capuleto. ${ }^{58}$

A pesar de la divergencia entre la opinión de Urbán y Koltai pienso que el espectáculo sí que tiene algunas soluciones memorables y laudables que $-\mathrm{y}$ en este aspecto comparto más bien el juicio del último crítico nombrado- contribuyen en gran medida a la estilización de la historia. Entre éstas destacaría el escenario de la dirección de Rusznyák, que es un espacio interesante, una arena miniaturista, semejante a un ruedo de una plaza de toros alrededor del cual está sentado el público. Los actores salen y entran por las dos salidas del ruedo, pero cuando no actúan, están también presentes, colocados entre los espectadores. También la última escena nos evoca marcadamente el mundo de las corridas, cuando los cuerpos de los hombres muertos se les tiran por el suelo como los toros matados. Ya antes de comenzar la función, se invita a los espectadores a una corrida de toros - pues, la hispanización del espacio ya está hechamientras que al terminar se repite la invitación, pero esta vez a un banquete funerario.

\footnotetext{
${ }^{54}$ Idem.

55 Tamás KOLTAI, "Benne vannak a korban”, op. cit.

${ }^{56}$ García Lorca admiraba mucho a Shakespeare y expresó su homenaje ante él en más obras suyas. Por ejemplo, en El público es múltiple la referencia a la obra del gran daramturgo inglés, al evocar Romeo y Julieta o El sueño de una noche de verano.

${ }^{57}$ Éva Veronika KALAPOS, "Boldogtalan szerelem és izzó, elfojtott gyűlölet", 26 de diciembre de 2008, asequible en: http://www.prae.hu/prae/articles.php?aid=1657, fecha de consulta: 16 de junio de 2014.

${ }^{58}$ Balázs URBÁN, "Már megint a duende”, op. cit.
} 
Bodas de sangre de Federico García Lorca en las tablas húngaras.

Algunas representaciones memorables entre 1957-2014

Es evidente que en ambos eventos el anfitrión es la muerte. A los invitados -los espectadores- de la fiesta mortuoria les esperan mesas llenas de comida en la entrada del teatro, así pueden compartir el luto de los personajes dramáticos y sentirse como si fueran realmente participantes de la tragedia.

Otro recurso escénico logrado es el uso de la harina blanca -en lugar de arena- que forma una pequeña loma en el ruedo y que esconde los instrumentos dramáticos, entre ellos también el cuchillo asesino, que emerge del fino polvo. Esta solución despierta involuntariamente el recuerdo de la teoría de García Lorca sobre el teatro bajo la arena, evocada aquí en su materialidad verdadera. Además, el espacio (el ruedo) y el color blanco (la harina) se armonizan perfectamente con la corrida siniestra y el cromatismo (blanca sábana, cal, nieve) del poema Llanto por Ignacio Sánchez Mejías. Igualmente, también "la sangre de Ignacio sobre la arena" recibe resonancia en un hermoso cuadro del espectáculo cuando los hilos de sangre se enredan por el suelo blanco bajo los cuerpos tendidos de los dos hombres.

\section{Bodas de sangre en el teatro Magyar Színház (2013)}

La dirección de Ádám Horgas en el teatro de cámara Sinkovits Színpad mezcla el tradicional teatro de prosa con algunas interesantes soluciones del teatro de movimiento. Así, texto, música y coreografía forman una unidad impresionante aunque es imposible dejar fuera de mención algunos elementos de distanciamiento del espectáculo. ${ }^{59}$

Entre las soluciones logradas del espectáculo mencionaría en primer lugar el inicio de la obra que es especialmente llamativo: una escena de fotografía post mortem, ${ }^{60}$ algo que estaba muy de moda a finales del siglo XIX, a comienzos del siglo XX. Una familia posa delante de la cámara para eternizar un momento horroroso de la vida familiar. ${ }^{61}$ Todos llevan unas máscaras espantosas menos los dos muertos envueltos de gasa manchada de sangre y el Novio. Las fotos en blanco y negro luego aparecen en el fondo teniendo a lo largo de la función un importante papel dramatúrgico.

Después, en la escena de la Madre y el Novio, llegamos a conocer el conflicto de más generaciones que vibra entre las dos familias: los Félix mataron ya al marido y al otro hijo de la Madre. Así cobra sentido también la escena inicial -ausente del texto

59 Véase las fotos del espectáculo en: http://www.magyarszinhaz.hu/galeria/category/59vernasz, fecha de consulta: 6 de junio de 2014.

${ }^{60}$ Este tipo de fotografía moribunda, aunque en nuestros días parece escalofriante, en el momento de su popularidad era natural, y simbolizaba la mentalidad de la gente de aquel entonces y su relación con la muerte. Generalmente, las fotos mortuorias siguieron tres modelos según la manera como se retrataban al sujeto: simulando vida, simulando estar dormido o en su estado natural.

${ }^{61} \mathrm{El}$ director acertó muy bien esta escena porque la foto en blanco y negro, según mi opinión, alude muy expresivamente a la noticia del periódico sobre los hechos de Nijar leídos por García Lorca.

92 | Acta Hispanica 19: 79-100, 2014, ISSN: 1416-7263 


\section{Eszter Katona}

lorquiano ${ }^{62}-$, aludiendo al pasado de las dos familias y explicando la aversión que la Madre siente hacia su futura nuera, que fue novia de un descendiente de los Félix. La foto con los muertos queda proyectada durante toda la escena sugiriendo que se trata no solamente de un recuerdo instantáneo en el álbum familiar, sino que advierte a los vivos de que no se olviden de la venganza en ningún momento de su vida.

El director aprovecha al máximo la técnica de la mencionada fotografía post mortem, momento inicial del espectáculo, ya que durante la escena de la huida y persecución, los dos muertos -el padre y el hermano del Novio- de la foto proyectada a la pared se reaniman, dando consejos al Novio. Así, en el lugar de los tres Leñadores lorquianos que funcionan como el coro de las tragedias griegas- aparecen los parientes asesinados por los Félix, subrayando aún más el mandado moral de la venganza. Luego, también la última escena repite la misma situación de la fotografía, pero esta vez los dos muertos son el Novio y Leonardo. Así, la foto después de la muerte enmarca toda la historia, indicando la repetición cíclica de la vida.

Del reparto lorquiano es interesante destacar a la figura de la Madre, una mujer dominante que expresa el dolor maternal causado por la pérdida de sus hijos. Por el contrario, la Madre de este estreno es mucho más débil y vulnerable gracias, tal vez, por su ceguera, invención propia del director. La mujer anciana tiene sus ojos abiertos durante todo el tiempo y tiene dos líneas rojas trazadas verticalmente en su cara, desde los ojos hasta el mentón. Las lágrimas de sangre, el rostro impasible y su vestido negro pueden evocarnos el efecto del teatro de pantomima.

Otra curiosidad en la distribución de los papeles es la mezcla del papel de la Criada y el de la Muerte. Cuando la actriz personifica a la primera tiene una relación ambigua con la Novia. Está preparándola para la boda pero parece que siente celos por su casamiento. En el momento cuando la Criada peina el pelo de la Novia aparece entre las dos mujeres incluso una relación lésbica que repite también cuando la Novia está hablando con su ex amante, mientras que la Criada está acariciándola entre sus piernas. ${ }^{63}$ El otro papel, el de la Muerte, personificada por la misma actriz que aparece en el ropaje de la Criada, lleva un antifaz de calavera. Su aspecto siniestro será horrible en la escena de la huida, cuando aparece en el bosque estilizado en una danza macabra entre unas figuras de movimiento animalístico que llevan máscaras de lobos.

Ádám Horgas utiliza frecuentemente en su escenografía el agua y el fuego, dos elementos cósmicos con significados simbólicos del mundo lorquiano. En la introducción del presente ensayo hemos visto como caracteriza la Novia a sus dos pretendientes y su propia pasión, utilizando justamente el valor del agua y del fuego. La

${ }^{62}$ García Lorca alude al rencor entre las dos familias solamente en el diálogo entre el Novio y su Madre y en la escena de ésta última con la Vecina.

63 Algunos directores húngaros (Judit Galgóczy, Teatro Csokonay, Debrecen, 2005; Imre Csiszár, Estudio Ericsson, Budapest, 2007) utilizan esta alusión al amor lésbico sobre todo en las interpretaciones de La casa de Bernarda Alba para aumentar el erotismo sofocado de las hijas encerradas por su madre tirana. (Eszter KATONA, op. cit., 111-112.) 
Bodas de sangre de Federico García Lorca en las tablas húngaras.

Algunas representaciones memorables entre 1957-2014

joven se describe a sí misma como "una mujer quemada" o "una muchacha acariciada por el fuego", mientras que el Novio será igualado a "un poquito de agua" o a "un niñito de agua". La figura de Leonardo y su fuerza se engrandecen a través de imágenes como "un río oscuro lleno de ramas", comparándole a un "golpe de mar".

En la interpretación de Horgas, el agua aparece sobre todo por su carencia y por la enorme sed que causa su ausencia. Es llamativo también que en el centro de la escena haya colocado un pozo artesiano, de color rojo que será el lugar de encuentro de los dos hombres rivales. Es importante, sin embargo, que este pozo está seco, no da ni una gota de agua. Horgas en este punto enlaza la simbología del agua (que da vida) y del cuchillo (que da muerte), ya que el Novio intenta reparar el pozo con su cuchillo, dejándolo clavado en el hueco del pozo, insinuando ya algo siniestro. El agua recibe mucha importancia además en la escena de las nupcias: los invitados llegan y todos, como un regalo de boda, dan un vaso de agua a la novia que lo bebe enseguida calmando, al parecer, su sed insaciable. Es evidente, sin embargo, que esta sed no se debe solamente al clima insoportable, sino más bien al fuego interior de la mujer que unos tragos de agua no pueden apagar.

El otro elemento cósmico, el fuego, aparece por un lado en los diálogos aludiendo al calor sofocante de la localidad andaluza "echan fuego las paredes" y en la pasión desmesurada de la Novia y su antiguo amante ¡Ay, qué lamento, qué fuego / me sube por la cabeza!". Por otro lado, el director visualiza también el fuego a través de unas proyecciones muy expresivas durante el diálogo entre Leonardo y su mujer. Aquí, las llamas, compaginadas con una música muy chocante, expresan el frenesí erótico del hombre seductor. También la posición a cuatro pies de la mujer de Leonardo y el movimiento del hombre que imita el galope vehemente de un caballista a la grupa de su caballo aumentan este sentido fuertemente sexual.

Las canciones y bailes -o tal vez sea más exacto hablar de movimientos- rituales forman otros momentos dignos de aplauso. ${ }^{64}$ La canción de cuna de la Madre y la Suegra, los bailes nupciales y el coro de los Leñadores dan también el gran lirismo del drama lorquiano y son unas escenas con un denso lenguaje metafórico. Este hecho siempre dificulta el trabajo del director y del coreógrafo que, en este caso, son el mismo, ya que Ádám Horgas cumple ambas funciones. En la escena de la canción de cuna cantada por la Mujer y la Suegra de Leonardo el director intensifica el carácter siniestro del texto original, visualizando el galope del caballo -la escena mencionada más arriba al tratar la proyección del fuego- con la colocación de la pareja en una posición densamente erótica. La combinación del lirismo de la nana y la música hiriente del galope metafórico es verdaderamente escalofriante. Resulta horrorosa también la aparición del hijo dormido, que parece más bien un niño muerto. Colocándole en una

${ }^{64}$ Ildikó Hámori, en el papel de la Madre opina que la mayor fuerza de la dirección reside justamente en la combinación del teatro de prosa con elementos rituales de la música y del movimiento. Véase en el vídeo sobre el espectáculo: http://www.szinhaz.tv/series/magyar_szinhaz/vernasz, fecha de consulta: 6 de junio de 2014 .

94 | Acta Hispanica 19: 79-100, 2014, ISSN: 1416-7263 


\section{Eszter Katona}

bandeja sobre la cabeza de la Suegra (en vez de una cuna) parece como si el bebé estuviera en un tanatorio. Con esta escena Horgas hace alusión, en mi opinión, a la inicial foto post mortem.

Otro momento muy efectivo es la escena de la huida de los dos jóvenes que, en el texto de García Lorca, se desarrolla en un bosque iluminado siniestramente por la Luna, un personaje alegórico. La concepción dramatúrgica del estreno de Magyar Színház da mucha mayor fuerza a la Luna, poniéndola en la escena no solamente en el bosque, sino también en otros momentos del espectáculo. El disfraz que lleva la actriz que personifica el astro nocturno tiene dos caras: una blanca y redonda (luna llena) que según el texto de Lorca ayuda al Novio iluminando el bosque denso, y la otra roja (media luna) que alude directamente a la luna que quiere beber de la sangre de los fugitivos "Pues esta noche tendrán / mis mejillas roja sangre."

En el texto original el caballo de Leonardo recibe sentido especial no solamente en la nana ya mencionada sino también en el rapto de la Novia. Horgas también logra utilizar el valor sexual de este animal así que coloca a la pareja enamorada a horcajadas en una mesa ${ }^{65}$ volteada. La lentificación de los movimientos de los jóvenes junto a su erotismo lírico tiene también un efecto marcadamente fílmico. La relación entre esta escena y la de la mencionada canción de cuna combinada con el galope frenético de Leonardo es indiscutible.

A pesar de las soluciones muy logradas del espectáculo, no puedo pasar por alto la mención de algunos extraños elementos de distanciamiento, a veces inexplicables. Uno de estos es cuando entra en la escena la vecina con un carrito de compras y durante el diálogo entre ella y la Madre saca de su bolso un desodorante roll-on. Es evidente que este último quiere insinuar el calor y el sudor (pero, ¿por qué una alusión tan obvia?), sin embargo, el primero, el carrito, no recibe ningún sentido en mi interpretación. En la escena de bodas, el Novio lleva un traje completamente negro y unos zapatos rojos. Este contraste de los colores negro y rojo -alusión evidente al color del luto y de la sangre -no sólo llama atención de los espectadores, sino también la de la Novia porque ésta, saliendo al parecer de la solemnidad del momento, le pregunta en seguida al hombre por qué ha elegido estos zapatos.

La razón de todos estos elementos ajenos, por un lado, puede ser-como nos explica en una entrevista Krisztina Szalay ${ }^{66}$ que personifica la Suegra- que el director quiere mostrar, junto a la tragedia, el humor de todos los días. Es decir, el llanto y la risa son dos emociones inseparables desde los comienzos del género dramático que se complementan para llegar a la catarsis final. Horgas logra el encuentro más evidente de estas dos facetas en la escena del loco del pueblo, un personaje que no aparece en la

\footnotetext{
${ }^{65}$ Un elemento del decorado que está presente en todos los momentos del espectáculo y que, a veces, funciona como una simple mesa (ofreciendo comida y bebida a los invitados) o, en otros momentos, como un espejo (aprovechando la superficie reflejante), o como la grupa del caballo estilizado.

${ }^{66}$ El tráiler sobre el espectáculo puede verse en: http://www.szinhaz.tv/series/magyar_szinhaz /vernasz, fecha de consulta: 6 de junio de 2014.
} 
Bodas de sangre de Federico García Lorca en las tablas húngaras.

Algunas representaciones memorables entre 1957-2014

lista de dramatis personae de García Lorca. Cuando el chico discapacitado llega a la boda con una copa de agua en su mano, pero en su torpeza se cae y el suelo absorbe el agua, la risa feliz de todos los invitados se convierte de repente en un silencio dramático. ${ }^{67} \mathrm{~A}$ través de este silencio la comicidad se transforma en tragedia en un solo segundo.

Por otro lado, reflexionando sobre la idea brechtiana en cuanto al distanciamiento, podríamos considerar este método, es decir, el uso de estos objetos (desodorante, cochecito, zapatos llamativos), contrario a la inmersión de los espectadores, esto es, justamente opuesto a los procedimientos que facilitan la purificación aristotélica al final de una obra teatral.

En conclusión, la dirección de Ádám Horgas logra compaginar el realismo de una historia trágica con el lirismo poético a través de unas escenas imborrables de nuestra memoria. El cromatismo de su espectáculo evoca los colores tan queridos por el dramaturgo andaluz, el negro, el blanco y el rojo, como también es muy fiel a la simbología lorquiana del agua, del fuego y de la luna. La música y los efectos tanto sonoros como visuales del espectáculo son especialmente llamativos y, en su modernidad, pienso que logran acercar el mensaje lorquiano a los espectadores del siglo XXI.

\section{Conclusión}

Bodas de sangre, sin duda alguna, no es tan popular en Hungría como La casa de Bernarda Alba. ${ }^{68}$ En su excelente ensayo ${ }^{69}$ de 1957, László Németh busca la razón de esto en el hecho de que en esta tragedia los espectadores húngaros no pueden reconocerse, es decir, no sienten suya la situación conflictiva. Por supuesto, la dificultad dramatúrgica y estilística del drama -como hemos visto- tampoco facilita ni el trabajo de los directores ni la tarea receptiva de los espectadores. Sin embargo, yo pienso que el mensaje lorquiano es de vigencia eterna. Así, tenemos que buscar los motivos de esta incomprensión por parte del público húngaro más bien en las diferentes puestas en escena, lo que contribuye evidentemente a la recepción de una obra de teatro.

Además, para el siglo XXI, parece que la falta de autoidentificación mencionada por Németh, ha desaparecido y el público de hoy sí que puede captar la problemática de esta historia de pasión y honor. Detrás de este fenómeno, tal vez, hay factores sociológicos que están más allá de lo puramente artístico y teatral. No podemos tampoco excluir, quizá, que el arte dramatúrgico y el gusto del público húngaro ya no rechacen tan categóricamente todo lo que no se encuadre dentro de la concepción naturalista, tendencia dominante del arte teatral húngaro durante muchas décadas. El número relativamente elevado de estrenos de Bodas de sangre puede mostrar también este giro: cada vez más compañías y grupos aficionados, o semiprofesionales (de estudiantes

\footnotetext{
${ }^{67}$ http://www.szinhaz.tv/series/magyar_szinhaz/vernasz, fecha de consulta 6 de junio de 2014. 68 Véase el Anexo al final de este artículo. Para una comparación con la estadística sobre los estrenos de La casa de Bernarda Alba en Hungría véase: Eszter KATONA, op. cit., 127-129.

${ }^{69}$ Lászó NÉMETH, “García Lorca színpada”, in: Nagyvilág, 1957, 6, 899-918.
} 
de escuelas dramáticas) ponen en su programación esta pieza. Igualmente es sorprendente el crecimiento de las adaptaciones de la obra a diferentes formas artísticas que caben entre las paredes de un teatro.

Al cuadro complejo de la recepción húngara de esta obra maestra de Federico García Lorca pertenecen, por supuesto, también los estrenos en idioma húngaro de las compañías fuera de nuestras fronteras. También estos grupos de vez en cuando ponen en su repertorio la tragedia lorquiana y en su concepción podemos descubrir a veces la huella de su cultura folclórica. Sin detallar este aspecto de la recepción, de la última década de nuestro siglo mencionaría la dirección de Mona Chirila (2001, Kolozsvár), ${ }^{70}$ la de József Czajlik (2003, Novi Sad) ${ }^{71}$ y la de László Görög (2006, Komárom), ${ }^{72}$ como demostración de que también en los teatros rumanos, serbios y eslovacos tiene vigencia esta pieza fascinante.

Obviamente, las diferentes adaptaciones del drama como, por ejemplo, a la ópera o al teatro de baile y movimiento enriquecen muchísimo la recepción húngara de la obra lorquiana. Existen numerosos ejemplos también de éstas, sin embargo, en este ensayo no puedo analizar en su profundidad la riqueza y la expresividad de todas estas formas artísticas. En la conclusión, sin embargo, no puede faltar por lo menos la mención de la ópera merecidamente famosa de Sándor Szokolay, ${ }^{73}$ con el título Vérnász, escrita en 1964 y estrenada hasta nuestros días en más de veinte países del mundo, un éxito sin par en la historia de la ópera húngara.

Igualmente, las adaptaciones al teatro de baile pueden formar la recepción y contribuir mucho a la popularidad de García Lorca en Hungría. Entre éstas también podemos encontrar muchas versiones, algunas muy memorables como, por ejemplo, la coreografía de Péter Uray con el título Vendetta (Compañía Panboro, 1999), la paráfrasis folclórica de

\footnotetext{
${ }^{70}$ Hajnal SZILVESZTER, "Halálos eljegyzés", in: Szabadság, 20 de marzo de 2001; Csaba NÁNÓ, "Vérnász a magyar színházban", in: Szabadság, 9 de abril de 2001; Kinga KELEMEN, "Szerelem és halál", in: Krónika, 19 de marzo de 2001; Adrienn DARVAY NAGY, "Kolozsvári napló - Vérnász", in: Criticai Lapok, 2002, 4-5, asequible en: http://criticailapok.hu/index.php?option=com_content \&view $=$ article\&id $=34014$, fecha de consulta: 17 de junio de 2014 .

71 László GEROLD, "Vérnász", in: Híd, 23 de noviembre de 2003, 1340-1343, asequible en: http://adattar.vmmi.org/cikkek/17383/hid_2003_11_23_gerold.pdf, fecha de consulta: 17 de junio de 2014. Además, véase el archivo del teatro: http://www.uvszinhaz.co.rs/?page=eloadas \&Eloadas $\mathrm{ID}=82$, y la galería de fotos: http:/ $/$ www.theater.hu/index.php?mode=galeria\&sorozat_id=364\&sub =sorozat\&id=364\&page $=1$, fecha de consulta: 17 de junio de 2014 .

72 András VERÉB, "Vérnász anya nélkül”, asequible en: http://szinhaz.hu/hatarontul/13964, fecha de consulta: 17 de junio de 2014; galería de fotos y vídeo: http://www.jokai.sk/eloadas23Vernasz.html, fecha de consulta: 17 de junio de 2014.

${ }^{73}$ El compositor húngaro murió en 2013 así no pudo vivir el cincuenta aniversario de su composición Vérnász: La Ópera Nacional Húngara, para homenajear al recientemente fallecido Szokolay, puso en su programación la obra para el otoño de 2014, bajo la dirección de Balázs Kovalik. En un ensayo aparte proyecto el análisis de este drama musicalizado hace un medio siglo, buscando el secreto del éxito de puestas en escena concretas desde 1964 hasta 2014.
} 
Bodas de sangre de Federico García Lorca en las tablas húngaras.

Algunas representaciones memorables entre 1957-2014

la compañía de danza Háromszék Néptáncegyüttes, dirigida y coreografiada por László Bocsárdi (2000), o la trilogía sobre la sangre del ya mencionado Péter Uray, con el título Vérednek ize (El sabor de tu sangre, 2003) cuya primera parte escenifica la obra lorquiana a través del lenguaje corporal del movimiento. ${ }^{74}$ Sin duda alguna, el análisis de todo eso merecería mucha mayor atención por parte de nuestros historiadores de teatro.

\footnotetext{
${ }^{74} \mathrm{El}$ repaso de las mencionadas adaptaciones al teatro de baile y movimiento de Bodas de sangre lo proyecto también en otro artículo.
} 
Anexo: Bodas de sangre (teatro de prosa y adaptaciones) en los teatros húngaros (1957-2014)

\begin{tabular}{|c|c|c|c|}
\hline Fecha & Teatro/compañía & Director/a & Género/ tipo \\
\hline 1957 & Teatro Nacional de Budapest & Endre Marton & Prosa \\
\hline 1964 & $\begin{array}{l}\text { Ópera Nacional Húngara, } \\
\text { Budapest }\end{array}$ & András Mikó & $\begin{array}{l}\text { Ópera de Sándor } \\
\text { Szokolay }\end{array}$ \\
\hline 1969 & Teatro Szigligeti, Szolnok & Gábor Székely & Prosa \\
\hline 1981 & Teatro Jókai, Békéscsaba & Béla Udvaros & Prosa \\
\hline 1983 & Escena Ódry, Budapest & László Gergely & Prosa \\
\hline 1986 & Teatro Nacional de Szeged & Géza Oberfrank & $\begin{array}{l}\text { Ópera de Sándor } \\
\text { Szokolay }\end{array}$ \\
\hline 1994 & Escena Origó, Budapest & Árpád Schilling & Prosa \\
\hline 1996 & Teatro Új Színház, Budapest & Eszter Novák & Prosa \\
\hline 1999 & Compañía Panboro ${ }^{75}$ & Péter Uray & Teatro de movimiento \\
\hline 2000 & $\begin{array}{l}\text { Compañía de baile folclórica } \\
\text { Háromszék Néptáncegyüttes }\end{array}$ & László Bocsárdi & $\begin{array}{l}\text { Adaptación al baile } \\
\text { folclórico }\end{array}$ \\
\hline 2000 & $\begin{array}{l}\text { Compañía Vareso aver } \\
\text { (antecedente del teatro } \\
\text { Maladype) }\end{array}$ & Zoltán Lendvai & Prosa \\
\hline 2001 & Teatro Nacional de Szeged & Balázs Kovalik & $\begin{array}{l}\text { Ópera de Sándor } \\
\text { Szokolay }\end{array}$ \\
\hline 2001 & $\begin{array}{l}\text { Teatro Nacional Húngaro de } \\
\text { Kolozsvár }\end{array}$ & Mona Chirila & Prosa \\
\hline 2001 & $\begin{array}{l}\text { Teatro Móricz Zsigmond, } \\
\text { Nyíregyháza }\end{array}$ & Péter Forgács & Prosa \\
\hline 2003 & $\begin{array}{l}\text { Compañía Panboro y la } \\
\text { compañía de estudiantes de la } \\
\text { Universidad Babes-Bolyai, } \\
\text { Kolozsvár }^{76}\end{array}$ & Péter Uray & Teatro de movimiento \\
\hline 2003 & $\begin{array}{l}\text { Teatro Katona József, } \\
\text { Budapest }^{77}\end{array}$ & Péter Uray & Teatro de movimiento \\
\hline 2003 & $\begin{array}{l}\text { Ópera Nacional Húngara, } \\
\text { Budapest }\end{array}$ & Balázs Kovalik & $\begin{array}{l}\text { Ópera de Sándor } \\
\text { Szokolay }\end{array}$ \\
\hline 2003 & $\begin{array}{l}\text { Teatro de la Universidad de } \\
\text { Artes Escénicas de } \\
\text { Marosvásárhely }\end{array}$ & Elemér Kincses & Prosa \\
\hline
\end{tabular}

75 Título de la producción: Vendetta.

${ }^{76}$ Título de la producción: $V$ endetta.

${ }_{77}$ Título de la producción: Vérednek ize (Sabor de tu sangre). 
Bodas de sangre de Federico García Lorca en las tablas húngaras.

Algunas representaciones memorables entre 1957-2014

\begin{tabular}{|c|c|c|c|}
\hline 2003 & Teatro Húngaro de Novi Sad & József Czajlik & Prosa \\
\hline 2004 & $\begin{array}{l}\text { Festival de Teatros Húngaros } \\
\text { más allá de las fronteras, } \\
\text { Kisvárda, Compañía de la } \\
\text { Universidad de Artes } \\
\text { Escénicas de Marosvásárhely }\end{array}$ & Elemér Kincses & Prosa \\
\hline 2006 & Teatro Jókai, Komárom & László Görög & Prosa \\
\hline 2008 & Teatro Honvéd, Budapest & Gábor Rusznyák & Prosa \\
\hline 2008 & $\begin{array}{l}\text { Teatro Katona József, } \\
\text { Kecskemét }^{78}\end{array}$ & Dóra Barta & Teatro de movimiento \\
\hline 2010 & $\begin{array}{l}\text { Ópera Nacional Húngara, } \\
\text { Budapest }\end{array}$ & Balázs Kovalik & $\begin{array}{l}\text { Ópera de Sándor } \\
\text { Szokolay }\end{array}$ \\
\hline 2011 & Teatro Csűrszínház, Mikháza & Viola Török & $\begin{array}{l}\text { Adaptación al baile } \\
\text { folclórico }\end{array}$ \\
\hline 2012 & $\begin{array}{l}\text { Encuentro de las Universidades } \\
\text { de Artes Escénicas, estudiantes } \\
\text { de la Universidad Babes-Bolyai, } \\
\text { Kolozsvár }\end{array}$ & István Albu & Prosa \\
\hline 2013 & Escena Ódry, Budapest & Csaba Horváth & Prosa \\
\hline 2013 & $\begin{array}{l}\text { Teatro Magyar Színház, } \\
\text { Budapest }\end{array}$ & Ádám Horgas & Prosa \\
\hline
\end{tabular}

\footnotetext{
78 Título de la producción: García Lorca ház̧a (La casa de García Lorca).
} 